J. Clin. Chem. Clin. Biochem.

Vol. 20, 1982, pp. 813-815

\title{
Eine Methode zur gaschromatographischen Bestimmung der lang- und mittelkettigen freien Fett- säuren im Serum
}

\author{
Von P. Radermacher, H. Grote, F. Susanto und H. Reinauer
}

Lehrstuhl für Klinische Biochemie und Biochemische Abteilung des Diabetes-Forschungsinstituts, Düsseldorf

(Eingegangen am 22. März/20. Juli 1982)

Zusammenfassung: Die Konzentrationen der freien Fettsäuren im Serum werden nach Veresterung mit BortrifluoridMethanol gaschromatographisch bestimmt. Das beschriebene Analyseverfahren erfaßt nach dünnschichtchromatographischer Vorreinigung der Serumlipidfraktionen selektiv die mittel- und langkettigen freien Fettsäuren. Das Analyseverfahren wurde auf Rịchtigkeit und Präzision überprüft und eignet sich zur Analyse der Fettsäurekinetik im Blut nach Lipidinfusionen.

\section{A method for the gas chromatographic determination of long and medium chain free fatty acids in serum}

Summary: Free fatty acids in serum were determined by gas chromatography after esterification with boron trifluoride-methanol. Following prepurification of the serum lipid fractions by thin layer chromatography, the described analytical procedure selectively determines the medium and long chain free fatty acids. Accuracy and precision were tested. The method is suitable for the analysis of fatty acid kinetics in blood, following lipid infusions.

\section{Einführung}

Im Rahmen von Infusionsversuchen mit Lipidemulsionen interessierte die Kinetik der freien Fettsäuren im Serum für die Beurteilung der intravasalen Lipolyse. Auf̣grund der unterschiedlichen Zusammensetzung der Lipidkomponenten - mittel- bzw. längkettige Triglyceride - in den infundierten Emullsionen war für unsere Fragestellung eine Meß- und Probenaufbereitungsmethode erforderlich, die auch die mittelkettigen freien Fettsäuren erfaßt. Arbeiten über die Analyse von langkettigen freien Fettsäuren und von Gesamtfettsäuren liegen vor $\left.(1-3)^{3}\right)$. Zièl dieser Arbeit war es, ein Probenaufbereitungsverfahren aufzubauen, das selektiv neben den lanğkettigen auch die mittelkettigen freien Fêttsäuren erfaßt.

\section{Materialien und Analysengang}

Alle Substanzen, soweit nicht anders vermerkt, waren von p.a. Reinheit und wurden von der Fa. Merck bezogen.

Extraktion der freien Fettsäuren

Zur Fällung der Proteine und zur Extraktion der freien Fettsäuren wurde ein Lösungsmittelgemisch aus Isopropanol, $\mathrm{n}$-Heptan und $0,5 \mathrm{~mol} / \mathrm{l}$ Schwefelsäure (Volumina,
$200 \mathrm{ml}+50 \mathrm{ml}+5 \mathrm{ml}$ ) verwendet (4). Um die freien Fettsäuren möglichst quantitativ in die organische Phase zu überführen, wurde eine Natriumsulfat-gesättigte $1 \mathrm{~mol} / 1$ Schwefelsäure zugesetzt.

\section{Dünnschichtchromatographie}

Zur Vortrennung der Serumlipide wurden Kieselgel-60-DC-Platten der Fa. Merck verwendet, die mit Chloroform-Aceton $(1+1)$ vorgereinigt waren. Bei der Auftrennung der Lipidfraktionen bestand das Fließmittel aus n-Hexan, Diethylether und Eisessig (Volumina, $60 \mathrm{ml}+40 \mathrm{ml}+1 \mathrm{ml}$ ).

Als Referenzsubstanzen wurden Arachidonsäure (Reinheitsgrad 90\%), Linolsäure, Caprylsäure und Arachinsäure (alle Reinheitsgrad $99 \%$ ), bezogen von den Firmen Serva $\left(C_{20: 4}, C_{18: 2}\right)$ und Merck $\left(C_{8: 0}, C_{20: 0}\right)$, verwendet, aufgetragen als Gemische von Linolsäure mit Arachinsäure und Caprylsäure mit Arachidonsäure.

\section{Interner Standard}

Als interner Standard wurde je $50 \mu \mathrm{g}$ Nonansäure (Pelargonsäure $\mathrm{C}_{9: 0}$, Reinheitsgrad 99\%) der Fa. Sigma und Heptadecansäure (Margarinsäure $C_{17: 0}$, Reinheitsgrad 98\%) der Fa. Merck verwendet. Die beiden Standards waren gaschromatographisch einheitlich.

\section{Veresterung}

Die freien Fettsäuren wurden mit 10\% Bortrifluorid-Methanol (Bortrifluorid-Diethylether-Komplex in Methanol 20+80) nach Morrison verestert (5). 
Gaschromatographic

Dic Fettsïuremethylester wurden mit einem Gaschromatographen $\mathrm{L} 350$ der $\mathrm{Fa}$. Siemens mit einem Flammenionisationsdetektor analysiert. Es wurde eine Glaskapillarsäule $(49 \mathrm{~m})$ der Fa. WGA (Beschichtung WG 11) verwendet. Die Detektortemperatur betrug $250^{\circ} \mathrm{C}$, das Trägergas war Helium bei einem Druck von 1,5 bar (Messer Griesheim, 6,0).

\section{Probenvorbereitung}

Von einer Lösung, die 0,5 g/1 Pelargonsäure und 0,5 g/1 Margarinsäure in $\mathrm{n}$-Hexan enthält, werden $100 \mu \mathrm{l}$ unter Stickstoffstrom zur Trockne gebracht, $1 \mathrm{ml}$ Serum hinzugegeben und nach Durchmischen etwa 10 Stunden bei $4^{\circ} \mathrm{C}$ gehalten. Zum Serum werden $5 \mathrm{ml}$ der Extraktionslösung gegeben, nach Durclımischen $2 \mathrm{ml}$ der mit Natriumsulfat gesättigten $1 \mathrm{~mol} / 1$ Schwefelsäure und $5 \mathrm{ml} \mathrm{n}$-Hexan hinzugefügt. Nach zweiminütigem Schütteln auf einem Whirlmix wird die organische Phase abgehoben und in einen Spitzkolben überführt. Die wäßrige Phase wird mit $5 \mathrm{ml} \mathrm{n}$-Hexan nachex trahiert. Die vereinigte organische Phase (Volumen etwa $13 \mathrm{ml}$ ) wird unter Stickstoffstrom im Wasserbad bei etwa $35^{\circ} \mathrm{C}$ auf etwa $150 \mu$ l eingeengt und quantitativ auf die DC-Platte aufgetragen. Die Serumlipide und die Referenzsubstanzen werden mit dem angegebenen Fließmittel entwickelt. Die Zone der freien Fettsäuren wird von der Platte geschabt, und die Fettsäuren werden auf dem Kieselgel 5 Minuten bei $120^{\circ} \mathrm{C}$ mit etwa $3 \mathrm{ml}$ Bortrifluorid-Methanol verestert. Der Reaktionslösung werden etwa $4 \mathrm{ml}$ Wasser zugesetzt, um den Bortrifluorid-Die thyle ther-Komplex zu zerstören. Das so aufgeschwemmte Kieselgel wird über eine Fritte getrocknet, die in einem Saugfinger aufgefangene wäßrige Phase mit $3 \mathrm{ml} \mathrm{n}$-Hexan ausgeschüttelt. Die Fettsäuremethylester werden mit $2 \times$ je $5 \mathrm{ml} \mathrm{n}$-Hexan vom Kieselgel eluiert. Die vereinigte Hexanphase wird am Rotationsverdampfer zur Trockne eingeengt und in $50 \mu \mathrm{ln}$-Hexan aufgenommen.

Gaschromatographische Auftrennung und Auswertung Unter Zugabe von $\mathrm{C}_{20: 2}$-Methylester zur leichteren Identifikation von Eicosatrien- und Arachidonsäure wird $1 \mu \mathrm{l}$ der Fettsäuremethylesterlösung in die GC-Säule injiziert und mit einem Temperaturprogramm von $100-230^{\circ} \mathrm{C}$ bei $2^{\circ} \mathrm{C} / \mathrm{min}$ entwickelt.

Die Berechnung der Konzentrationen der einzelnen freien Fettsäuren erfolgte über Peakflächenvergleich unter Verwendung eines Autolab Minigrators der Fa. Spectra Physics. Die Konzentrationen der mittelkettigen Fettsäuren $\left(C_{8: 0}-C_{12: 0}\right)$ wurden mit Hilfe des internen Standards $C_{9: 0}$ berechnet, die der langkettigen Fettsäuren über den internen Standard $C_{17: 0}$.

\section{Ergebnisse}

\section{Rich tigkeit}

Um die Effizienz des Extraktionsverfahrens zu testen, wurden dem Serum 34,3 $\mu$ g einer ${ }^{14} \mathrm{C}$-markierten Caprylsäure (New England Nuclear, spezifische Aktivität $162,8 \mathrm{MBq} / \mathrm{mmol}=4,4 \mathrm{mCi} / \mathrm{mmol}$ ) zugesetzt. Nach typischem Analysengang wurde die Radioaktivität der aufbereiteten Probe in einem $\beta$-Counter gemessen (MR 300 der Fa. Kontron). Es wurden $63,2 \pm 6,6 \%$ der eingesetzten Radioaktivität wiedergefunden. Mit Hilfe des ebenfalls hinzugefügten internen Standards Pelargonsäure $(50 \mu \mathrm{g})$ wurde die Menge der eingesetzten radioaktiven Caprylsäure berechnet und dieser Wert mit der Einwaagemenge verglichen. Mit diesem Verfahren wurden $31,7 \pm 2,8 \mu \mathrm{g}$ Caprylsäure (VK $=8,8 \%$ ) entsprechend einer Wiederfindungsrate von $91,4 \pm 5,7 \%$ gefunden. Somit ist die Verwendbarkeit des internen Standards $C_{9: 0}$ für die
Analyse der mittelkettigen Fettsäuren erwiesen. Daher wurden die weiteren Analysen bzgl. der mittelkettigen Fettsäuren $\left(C_{8: 0}, C_{10: 0}, C_{12: 0}\right)$ mit dem internen Standard $\mathrm{C}_{9: 0}$ korrigiert.

' Zur weiteren Kontrolle wurde ein Pooolsẹrum mit einem Gemisch freier Fettsäuren aufgèstockt (Zusammensetzung siehe Tabelle $1 ; C_{10}$, Reinheitsgrad $98 \%$, $\mathrm{C}_{8}, \mathrm{C}_{12}, \mathrm{C}_{14}, \mathrm{C}_{16}, \mathrm{C}_{20}$ Reinheitsgrad $99 \%$, alle für biochemische Zwecke von der Fa. Merck, $\ddot{C}_{19}$ p.a. von der Fa. Serva, $C_{18: 1 \text { trans }}$ Reinheitsgrad $99 \%$ von der Fa. Sigma). Die Einwaagen und die Wiederfindung für die einzelnen Fettsäuren sind in Tabélle 1 dargestellt.

Tab. 1. Zusammensetzung des dèm Poolserum zugesetzten Fettsäuregemischs; Wiederfindungsrate absolut in $\mu \mathrm{g}$ und in $\%$ der Einwaage $(n=7)$.

\begin{tabular}{llllr}
\hline & & $\begin{array}{l}\text { Ein } \\
\text { waage } \\
\end{array}$ & & \multicolumn{2}{c}{ Wiederfindung } \\
& & $(\mu \mathrm{g})$ & $(\mu \mathrm{g})$ & $(\%)$ \\
\hline Caprylsäure & $\mathrm{C}_{8}$ & 46,8 & 40,8 & 87,2 \\
Caprinsäure & $\mathrm{C}_{10}$ & 54,0 & 60,9 & 112,9 \\
Laurinsäure & $\mathrm{C}_{12}$ & 56,4 & 58,9 & 104,4 \\
Myristinsäure & $\mathrm{C}_{14}$ & 56,7 & 61,1 & 107,7 \\
Palmitinäüre & $\mathrm{C}_{16}$ & 66,7 & 59,9 & 89,8 \\
Elaidinsäure & $\mathrm{C}_{18: 1 \text { trạns }}$ & 48,4 & 47,4 & 97,9 \\
Nonadekansäure & $\mathrm{C}_{19}$ & 39,0 & 37,7 & 96,7 \\
Arachinsäure & $\mathrm{C}_{20}$ & 51,8 & 47,8 & 92,3 \\
\hline
\end{tabular}

\section{Präzision}

Das Poolserum wurde wiederholt aufgearbeitet und für die einzelnen Fettsäuren der Variationskoeffizient der Konzentrationswerte bestimmt (n $=7$ ). Diese Präzisionsbestimmung wurde auch für die zugesetzten Fettsäuren durchgeführt. Die Resultate sind in Tabelle 2 dargestellt.

Tab. 2. Konzientrationen der einzelnen freien Fettsăuren des mit dem Fettsäuregemisch aufgestockten Poolserums $(\bar{x} \pm \mathrm{SD}$ in $\mathrm{mg} / \mathrm{l})$, Variationskoeffizient in $\%(\mathrm{n}=7)$ Angegeben ist die Differenz aus Gesamtkonzentration und Einwaage furr $C_{12}, C_{14}$ und $C_{16}$.

\begin{tabular}{|c|c|c|c|}
\hline & & $\begin{array}{l}\text { Konzen- } \\
\text { tration } \\
(\mathrm{mg} / \mathrm{l})\end{array}$ & $\begin{array}{l}\text { VK } \\
(\%)\end{array}$ \\
\hline $\begin{array}{l}\text { Caprylsäure } \\
\text { Caprinsäure } \\
\text { Laurinsäure } \\
\text { Myristinsäure } \\
\text { Palmitinsäure } \\
\text { Palmitoleiñsäure } \\
\text { Stearinsäure } \\
\text { Ölsäure } \\
\text { Ėlaidinsäure } \\
\text { Linolsäure } \\
\text { Linolensäure } \\
\text { Nọnadẹansäure } \\
\text { Arachinsäure } \\
\text { Arachidonsäure }\end{array}$ & $\begin{array}{l}C_{8} \\
C_{10} \\
C_{12} \\
C_{14} \\
C_{16} \\
C_{16: 1} \\
C_{18} \\
C_{18: 1 \text { eis }} \\
C_{18: 1 \text { trans }} \\
C_{18: 2} \\
C_{18: 3} \\
C_{19} \\
C_{20} \\
C_{20: 4}\end{array}$ & $\begin{aligned} 40,8 & \pm 1,3 \\
60,9 & \pm 2,9 \\
8,0 & \pm 4,0 \\
12,9 & \pm 3,6 \\
95,1 & \pm 11,8 \\
10,5 & \pm 1,0 \\
34,1 & \pm 4,6 \\
96,9 & \pm 9,7 \\
47,4 & \pm 2,7 \\
73,9 & \pm 4,8 \\
3,6 & \pm 0,5 \\
37,7 & \pm 0,9 \\
47,8 & \pm 3,1 \\
10,6 & \pm 1,8\end{aligned}$ & $\begin{array}{r}3,3 \\
4,8 \\
50,0 \\
28,2 \\
12,4 \\
9,0 \\
13,4 \\
10,0 \\
5,7 \\
6,5 \\
12,8 \\
2,4 \\
6,5 \\
16,9\end{array}$ \\
\hline
\end{tabular}


Ein typisches Chromatogramm der freien Fettsäuren im Serum während eines Infusionsversuches mit mittelkettigen Triglyceriden ist in Abbildung 1 dargestellt. Aus der gaschromatographischen Analyse wird erkennbar, daß Palmitin-, Stearin-, Ol- und Linolsäure, die normaler- weise den größten Anteil bei den freien Fettsäuren im Serum darstellen (etwa 90\%), unter der Infusion von mittelkettigen Triglyceriden auf einen Prozentsatz von etwa $40 \%$ reduziert sein können zugunsten der mittelkettigen Fettsäuren Capryl- bzw. Caprinsäure.

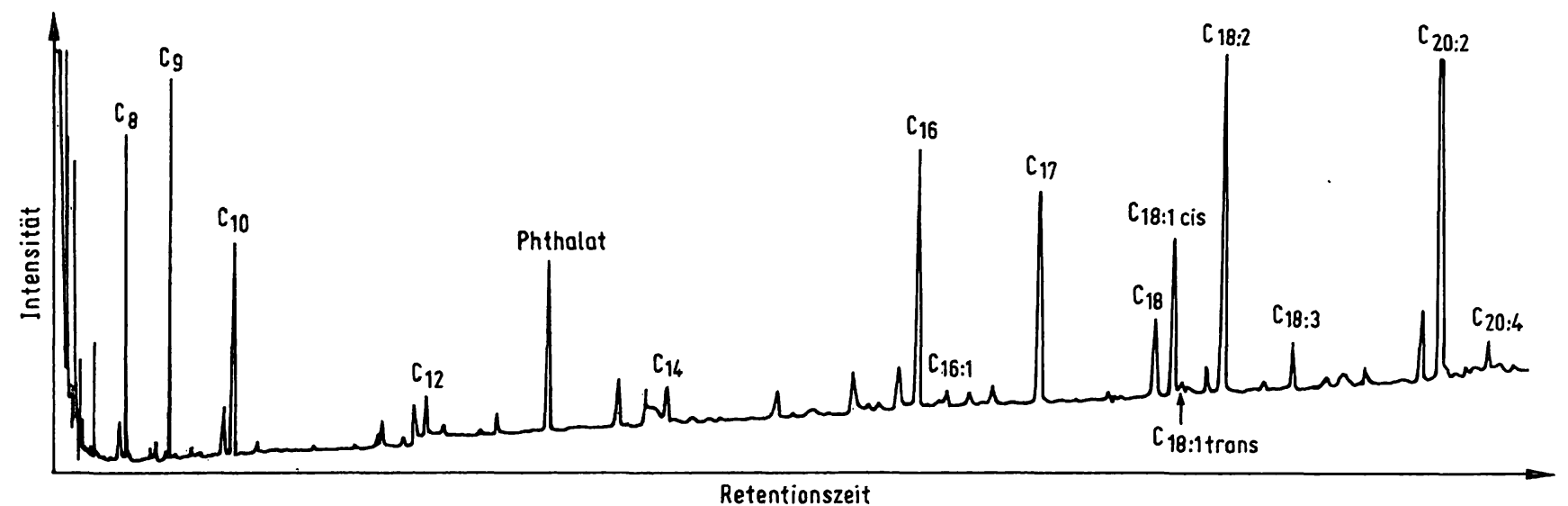

Abb. 1. Typisches Gaschromatogramm der freien Fettsäuren im Serum unter Infusion mittel- und langkettiger Triglyceride; die Fettsäuren liegen als Methylester vor.

\section{Diskussion}

Die hier vorgestellte Meß- und Probeaufbereitungsmethode hat das Ziel, die freien Fettsäuren des Serums zu erfassen unter Einschluß der mittelkettigen Fettsäuren Capryl-, Caprin- und Laurinsäure.

Die Derivatisierung ist einerseits vollständig, wie auch massenspektrometrische Kontrollen zeigten, und andererseits treten außer bei der Ölsäure keine unerwünschten Nebenreaktionen auf. Die geringe Menge Elaidinsäure lag quantitativ meist unter 1\%. Ob dieser Anteil Elaidinsäure tatșächlich auf eine Nebenreaktion zurückzuführen ist, oder ob es sich um präformierte Elaidinsäure handelt, kann nicht beantwortet werden.

Die relativ groß̣e Streụung der Wèrte für Laurin- und Myristinnsăure ist durch Verunreinigung aus dem Serum bedingt, die bislang nicht genauer identifiziert werden konntên. Da der Anteil dieser Fettsäuren jedoch untèr $5 \%$ der gesamten freien Fettsäuren im Serum liegt, konnte auf eine weitere Optimierung der Methode bezüglich dieser beiden Fettsäuren verzichtet werden. Zudem zeigen die Wiederfindungen von 104,4 bżw. $107,7 \%$, dạß diese beiden Fettsäuren quantitativ erfaßt werden.

\section{Literatur}

1. Grünert, A. (1975) Z. Klin. Chem. Klin. Biochem. 13, 407-412.

2. Olbermann, M. \& Grünert, A. (1976) Infusionstherapie 3, 210-214.
Die untere Nachweisgrenze für freie Fettsäuren mit der beschriebenen Methode kann mit $2 \mathrm{mg} / \mathrm{l}$ angegeben werden. Zwar ist eine Peakidentifikation in der Regel noch bei einer Konzentration von $1 \mathrm{mg} / \mathrm{l}$ möglich, unterhalb der Grenze von $2 \mathrm{mg} / \mathrm{l}$ werden die Streuungen der Meßwerte jedoch zu groß, um verläßliche Werte zu ermöglichen (Streuungen SD $>20 \%$ ). Besonders berücksichtigt werden muß die Problematik für Laurin-bzw. Myristinsäure.

In der klinischen Routine ist vor allem die Bestimmung der Konzentrationen der langkettigen freien Fettsäuren von Bedeutung. Hierfür, insbes. zur Analyse von großen Probenserien, steht eine Methode zur Verfugung (1). Die von uns vorgestellte Methode ist für derartige Problemstellungen zu zeitaufwendig aufgrund der dünnschichtchromatographischen Vortrennung der Serumlipidfraktionen und wird daher für klinische Studien vorbehalten werden.

Mit der beschriebenen Methode gelang es, die Kinetik der einzelnen freien Fettsäuren im Blut nach Triglyceridinfusionen zu untersuchen.
3. Sailer, D. \& Berg, G. (1979) Infusionstherapie 6, 171-174.

4. Dole, V. \& Meinertz, H. (1960) J. Biol. Chem. 235, 2595-2599.

5. Morrison, W. \& Smith, L. (1964) J. Lipid Res. 5, 600-608.
Prof. Dr. H. Reinauer Diabetes-Forschungsinstitut Auf'm Hennekamp D-4000 Düsseldorf 


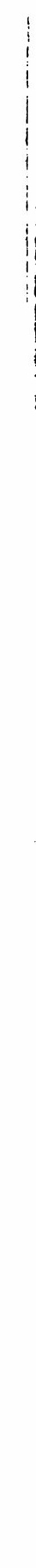

